\title{
Prefecturas, comisarías de campaña y construcción estatal en la Provincia de Buenos Aires (Argentina) a mediados del siglo XIX ${ }^{*}$
}

\section{Prefectures, Police Stations and State \\ Construction in the Province of Buenos Aires \\ (Argentina) in the Mid-19th Century}

\author{
Melina Yangilevich \\ (1) 0000-0003-2036-2503 \\ Instituto de Geografía, Historia y Ciencias Sociales \\ Instituto de Estudios Histórico Sociales \\ Conicet/Universidad Nacional del Centro de la Provincia de Buenos Aires, \\ Argentina \\ myangilevich@gmail.com
}

Resumen: El propósito del trabajo consiste en analizar la formación y consolidación del Estado en la provincia de Buenos Aires a mediados del siglo XIX a través del examen del funcionamiento de las prefecturas y comisarías de campaña. Para realizarlo, se utilizaron diferentes fuentes documentales editadas e inéditas. El análisis se centró en los factores que condicionaron la organización y funcionamiento de las prefecturas. Entre ellos, la incapacidad de las nuevas autoridades de construir legitimidad al interior de las comunidades debido a la débil presencia estatal y al papel desempeñado por los jueces de paz en la gobernabilidad de esos espacios. El estudio procura mostrar a partir del presente análisis que la construcción estatal fue el resultado de una negociación cotidiana en los espacios locales entre diversos actores políticos.

* Agradezco a Eugenia Molina y los evaluadores anónimos de la revista por sus comentarios y sugerencias. 
Palabras clave: prefecturas de campaña; comisarías; construcción estatal; Provincia de Buenos Aires; siglo XIX.

Abstract: The purpose of this article is to analyze the formation and consolidation of the state in the province of Buenos Aires in the mid-19th century by examining the functioning of prefectures and police stations. To this end, various published and unpublished documentary sources were used. The analysis focused on the factors that conditioned the organization and functioning of the prefectures. These include the inability of the new authorities to build legitimacy within communities due to the weak state presence and the role played by the judges of peace in the governance of these spaces. The study attempts to use the present analysis to show that state construction was the result of everyday negotiation in local spaces between diverse political actors.

Key words: campaign prefectures; police stations; state construction; Buenos Aires province; 19th century.

Fecha de recepción: 24 de diciembre de 2015 Fecha de aprobación: 8 de junio de 2016

\section{INTRODUCCIÓN}

$E^{1}$ 1 proceso de construcción estatal en América Latina constituye un tema transitado desde diferentes perspectivas dentro de la disciplina histórica. En las últimas décadas, los estudios realizados desde la historia política problematizaron la noción del origen del Estado como consecuencia necesaria de la evolución de la dinámica política anterior y posterior a los procesos revolucionarios de inicios del siglo xIx. De esta manera, cuestionaron la asociación entre historia política e historia del Estado, hasta entonces entendida como sinónimos. La renovación historiográfica implicó, por un lado, que los análisis se focalizaran en actores y periodos hasta entonces no abordados. Por otro, se ampliaron los espacios estudiados al considerar territorios alejados de los grandes centros políticos. Como consecuencia, los problemas de investigación se multiplicaron y complejizaron (Barriera, 2002; Palacios, 2007; Sabato, 2007). 
Uno de los temas que concentró el interés de los estudiosos fue el vínculo entre las autoridades centrales y los habitantes de los espacios locales. En relación con este problema, uno de los trabajos pioneros fue el de Gilberth Joseph y Daniel Nugent (1994). Allí compilaron diferentes estudios que atendían a los aspectos cotidianos de la construcción estatal y la negociación de la autoridad en el contexto de la revolución mexicana de principios del siglo $\mathrm{xx}$. Los autores plantearon la necesidad de repensar ese proceso atendiendo al papel desempeñado en él por la cultura popular. En su análisis, la construcción estatal se definió como un proceso cultural con consecuencias en el mundo material (p. 13). Ello sin dejar de considerar que el Estado no es en sí mismo un objeto que puede ser analizado. Por el contrario, propusieron indagar en las dimensiones procesales de su formación y evolución dinámica así como considerar las relaciones sociales concretas entendidas como el conjunto de prácticas, rituales e instituciones generadas al interior de un sistema de dominación capaz de imponer valores y significados (p. 20). Esta propuesta implicó considerar las relaciones de poder $-\mathrm{y}$ dentro de ellas las vinculadas a la construcción estatal-como necesariamente negociadas entre quienes lo detentaban y aquellos sobre quienes era ejercido (Falcón, 2015). Siguiendo estos postulados, otros estudios propusieron revisar el funcionamiento de las instituciones de control social, en tanto agencias estatales, así como su capacidad para imponer su poder al considerarlas como espacios de tensión y negociación (Di Liscia y Bohoslavsky, 2005).

En el marco propuesto por estos análisis, el propósito del presente trabajo consiste en analizar el proceso de organización, funcionamiento y desaparición de las prefecturas en el territorio bonaerense entre 1857 y 1859. Esta indagación pretende contribuir a la comprensión del proceso general de construcción estatal a través del estudio de una reforma política que pretendió reorganizar el gobierno de la campaña de Buenos Aires. La investigación permitirá poner el foco en la praxis política de actores casi anónimos aunque fundamentales en un territorio donde la autoridad y la obediencia fueron objeto de disputas cotidianas. Para ello, será necesario considerar a las prefecturas al interior del proceso de construcción estatal y en relación con las autoridades existentes, como comandantes y jueces de paz. La hipótesis que guía la indagación consiste en que la dinámica de esa experiencia estuvo supeditada por el grado de legitimación que los prefectos lograron construir al interior de las comunidades donde ejercieron sus cargos. Las razones de tal condicionamiento fueron diversas. En primer lugar, la debilidad del Es- 
tado y la escasez presupuestaria implicaron la ausencia de recursos de todo tipo. En segundo término, los prefectos eran foráneos a las comunidades donde debían desempeñarse, sin lazos de vecindad, arraigo o parentesco que les permitieran actuar sobre vínculos preestablecidos. De este modo, en las disputas establecidas con los jueces de paz por el control de diferentes funciones, las comunidades tendieron a sostener a estos últimos. En síntesis, el análisis propuesto pretende contribuir, en los términos propuestos por Jospeh y Nugent (1994), a la reflexión sobre la construcción estatal considerando los vínculos cotidianos de negociación de la autoridad.

El trabajo se encuentra dividido en tres partes, además de la introducción y las consideraciones finales. En la primera, se presentan de manera sumaria diversos estudios que analizaron la dinámica de funcionamiento de las jefaturas políticas fundamentalmente en México. Estos sirvieron de contexto a nuestro análisis y como insumos para repensar la problemática en el espacio bonaerense. En la segunda parte se aborda el complejo proceso de conformación de la provincia bonaerense en tanto espacio político así como el establecimiento de diferentes jurisdicciones y autoridades con el objetivo de ordenar el espacio y a quienes lo habitaban. En el último apartado se analiza la dinámica de la convivencia cotidiana de antiguas y nuevas autoridades con los vecinos de la campaña bonaerense así como los conflictos que se generaron entre ellos y las negociaciones que establecieron. Las fuentes documentales a analizar están conformadas por registros editados e inéditos. Los primeros consisten en la extensa producción normativa que rigió la implementación, el funcionamiento y el fin de la experiencia de prefecturas y comisarías de campaña. Por su parte, los documentos inéditos consisten, fundamentalmente, en correspondencia oficial intercambiada entre el gobernador Alsina, jueces de paz, prefectos y comisarios.

\section{PREFECTURAS Y JEFATURAS POLÍTICAS EN AMÉRICA LATINA DURANTE EL SIGLO XIX}

La importancia de las jefaturas políticas en la consolidación de los Estados fue señalada por diversos estudios que se ocuparon de esta problemática. Sin embargo, surgieron matices en las explicaciones sobre su origen. Algunos autores sostuvieron que la figura se originó en la Constitución de Cádiz de 1812 (Mecham, 1986, p. 143; Vilchis, 2012, p. 71). Otros historiadores, por el 
contrario, plantearon que esta institución se vinculaba con las reformas borbónicas, precisamente la Real Ordenanza de Intendentes de 1786 (Delgado Aguilar, 2004, p. 6). Más allá de su génesis, los estudios coincidieron en presentar a los prefectos como intermediarios entre las autoridades centrales y los espacios locales. Por ello, cumplieron un papel primordial en el diseño de una administración centralizada y jerárquica procurando organizar un gobierno eficaz que articulara las instancias de gobierno y contuviera las demandas de los espacios locales. El estudio más completo sobre esta figura fue el desarrollado por Romana Falcón (1992, 1998, 2007, 2015). Para esta historiadora los jefes políticos constituyeron un instrumento delineado para fortalecer los lazos de dominio del poder central y, en ese sentido, fungieron como intermediarios políticos permitiendo que fluyeran las decisiones de las autoridades centrales así como las demandas de los espacios regionales o locales (2015, p. 463). En la consideración de las elites gobernantes, las jefaturas políticas alcanzaron una cierta eficacia como una institución intermedia de la administración territorial (Bonaudo, 2008, p. 259). Por ello, las repercusiones de estos debates se difundieron en otros espacios latinoamericanos como Colombia (Vélez, 2012), Perú (Peralta, 2016) y Argentina, donde es posible encontrar que su implementación alcanzó resultados diversos (Bonaudo, 2008; Cucchi, 2014; Díaz, 1959; Pavoni, 2000; Tenti, 2010). Su función consistía en actuar como representantes del poder ejecutivo ante las comunidades locales y fungir como canal de trasmisión de sus demandas. Estos vínculos no carecieron de fuertes conflictos, sin embargo, su papel en la consolidación de las autoridades estatales fue relevante para la persistencia del cargo (Bonaudo, 2003).

En la provincia de Buenos Aires hubo un intento por replicar estas experiencias. Valentín Alsina, gobernador entre 1857 y 1859, presentó un proyecto de ley proponiendo la organización de las prefecturas de campaña (Díaz, 1959). El cargo de prefecto era equivalente al de jefe político, aunque Alsina eligió la denominación de origen francés antes que la española. Esta experiencia resulta relevante debido a que formó parte de una serie de reformas e innovaciones institucionales que tuvieron lugar en la provincia bonaerense y que estuvieron enmarcadas en el proceso de construcción estatal del periodo. A pesar de su importancia, las prefecturas de campaña no fueron objeto de un estudio en profundidad. Los análisis sobre el gobierno de las personas en el espacio rural bonaerense se centraron en los jueces de paz y los comandantes de frontera. Estas autoridades contaban con una fuerte le- 
gitimidad asentada en su extensa presencia que se remontaba a inicios de la década de 1820 (Fradkin, 2014; Garavaglia, 1999; Gelman, 2000).

\section{EL EQUIPAMIENTO POLÍTICO DEL TERRITORIO: PREFECTURAS, COMISARÍAS Y JURISDICCIONES}

En 1821 Bernardino Rivadavia, ministro de Gobierno de la Provincia de Buenos Aires impulsó un conjunto de reformas judiciales, militares y eclesiásticas con el propósito de construir una estructura estatal con características modernas (Ternavasio, 1998). Entre otras consecuencias implicaron la disolución de los cabildos ubicados en Buenos Aires y Luján. Ello implicó la segregación de papeles desempeñados en el marco de los ayuntamientos. Las funciones judiciales desempeñadas por estos quedaron distribuidas en dos instituciones. La baja justicia pasó a los jueces de paz, establecidos en cada partido. Las tareas eran las mismas que desempeñaban, hasta entonces, los alcaldes de la hermandad. Como instancia superior se encontraban los jueces letrados a cargo de jurisdicciones denominadas departamentos, que incluían un conjunto de partidos (Fradkin, 2009). Las funciones policiales fueron atribuidas a comisarios distribuidos en el territorio de la campaña (Rico, 2008).

Durante el periodo colonial, el mantenimiento del orden fue una preocupación constante de las autoridades y el diseño rivadaviano retomaba esa inquietud. Sin embargo, como en otros espacios americanos, la cuestión del territorio se tornó central. El gobierno decidió establecer diversas autoridades en la campaña, considerando que no resultaba posible controlarla desde la ciudad capital. A poco de su implementación, la justicia letrada y las comisarías presentaron un conjunto de problemas que las hicieron inviables (Fradkin, 2009). Los jueces letrados pasaron a residir de manera permanente en Buenos Aires, mientras que las funciones policiales quedaron en manos de los jueces de paz, situación que se prolongó hasta avanzada la segunda mitad del siglo xIx. Luego de estas reformas, el único cambio institucional importante hasta la década de 1850 consistió en la división y creación de nuevos partidos realizada por el gobernador Juan Manuel de Rosas, luego de un levantamiento considerable en el sur de la campaña bonaerense (Gelman, 2009). 
Entre 1852 y 1862 Buenos Aires permaneció separada de la Confederación Argentina ${ }^{1}$ en tanto estado independiente. Al igual que el resto de las autoridades provinciales, las bonaerenses se dedicaron a organizar diversas instituciones con el fin de construir un orden que se consideraba inexistente. Para Alsina este objetivo descansaba, en buena medida, en lo que Darío Barriera (2009) denominó el proceso de equipamiento político del territorio. Ello implicó la creación y puesta en vigencia de un conjunto de nuevas jurisdicciones y autoridades. Durante esos años se establecieron diversas instituciones que resultaron relevantes para la consolidación estatal. Entre ellas, cabría mencionar la organización de la justicia letrada en 1853 (Yangilevich, 2012); la aprobación de la constitución provincial; la creación de las municipalidades y la organización de las Guardias Nacionales ${ }^{2}$ (1854) así como el restablecimiento de las comisarías y la creación de las prefecturas en 1857. Estas disposiciones cristalizaron en una coyuntura de fuerte conflictividad en el territorio provincial. ${ }^{3}$ En este contexto, para las autoridades la cuestión del orden al interior del territorio provincial era un problema pendiente de resolución.

En buena parte de estas decisiones, Valentín Alsina tuvo una activa participación en tanto se desempeñó como legislador, miembro del Tribunal de Justicia -estos dos cargos de manera simultánea- y gobernador en dos ocasiones (1852 y 1857-1859). Cuando asumió su segundo mandato propuso reestablecer las comisarías y organizar las prefecturas de campaña. El propósito que perseguía era hacer efectiva la autoridad del gobierno provincial en el territorio rural de la provincia, un espacio visualizado como punto de apoyo del rosismo y, por tanto, fuente latente de disturbios y caos. En mayo de 1857 envió a la legislatura provincial el proyecto de creación de las

${ }^{1}$ Entre 1852 y 1862 la provincia de Buenos Aires se separó de la Confederación Argentina al no aceptar los términos del pacto de San Nicolás, base de la Constitución Nacional aprobada en 1853, que imponían la nacionalización de los ingresos de la Aduana porteña -principal fuente de recursos económicos-y de la ciudad de Buenos Aires como capital del Estado central (Bragoni y Míguez, 2010).

${ }^{2}$ La Guardia Nacional fue establecida por medio de un decreto del presidente Justo José de Urquiza en 1854 y debía responder a los mandos del Ejército Nacional, el que integraba formalmente junto al ejército de línea. Sin embargo, según Hilda Sabato (2010), dichas fuerzas fueron controladas por los gobiernos provinciales.

${ }^{3}$ La separación del Estado de Buenos Aires de la Confederación Argentina generó una tensión latente entre ambas, que se vio acentuada por un levantamiento militar en Buenos Aires (1854) y un ataque indígena (1855) debido al fin de las relaciones mantenidas con las autoridades luego del fin del gobierno de Rosas. 
comisarías. La mayoría de los legisladores coincidió en la necesidad de reestablecerlas para aprehender a "desertores, [...] vagos y cortar los delitos que se cometen con mucha repetición". ${ }^{4}$ Sin embargo, quienes presentaron algunas impugnaciones, como Rufino de Elizalde y Bartolomé Mitre, argumentaron que anteriormente la coexistencia de jueces de paz y comisarios había generado dificultades que llevaron a la desaparición de las comisarías debido a que las facultades de unos y otros no estaban delimitadas con claridad. Según afirmaron, en el nuevo proyecto se mantenía dicha imprecisión. El diputado Elizalde se preguntaba:

Por las leyes vigentes los Jueces de Paz, como son comisarios también han asumido las dobles atribuciones que cada uno de estos funcionarios tenían, ahora viene esta ley y dice: quedan establecidos los Comisarios de Campaña con atribuciones policiales, es decir, que del cúmulo de las que tenían los Jueces de Paz hay que separar lo que es puramente policial ¿y qué es lo que se entiende por atribuciones puramente policiales? hé ahí la dificultad, que no resuelve este artículo.

Las palabras de Elizalde ilustraron la indeterminación de las facultades de jueces de paz y comisarios establecidos en 1821 así como la duda sobre si la ley proyectada no repetiría aquello que no había sido efectivo. Finalmente, la propuesta fue aprobada de acuerdo al proyecto original. El artículo más discutido -el número 1- determinó que "todas las funciones policiales serán desempeñadas inmediatamente en la campaña por Comisarías en número de veinticinco, y los Juzgados de paz quedarán exonerados del ejercicio de ellas". En ningún apartado se determinaron cuáles serían las funciones policiales de los comisarios. ${ }^{5}$ La vaguedad en las definiciones de las atribuciones policiales dejó un amplio margen para que las autoridades las definieran. Para ello, se dictó un reglamento ${ }^{6}$ que buscaba limitar el poder de los jueces

${ }^{4}$ Sesión de la Cámara de Diputados del 15 de junio de 1857, Diario de Sesiones. Año de 1857, p. 190. Imprenta de La República, 1883, Buenos Aires. Todas las referencias a los debates corresponden a la misma sesión, salvo indicación en contrario.

${ }^{5}$ De esa división quedaron exceptuados los partidos de Junín, Bahía Blanca y Patagones por su ubicación en los espacios de frontera. Ley $\mathrm{N}^{\circ} 136$. Creación de comisarías y funciones de los jueces de paz (Ketzelman, y Souza, 1931, t. I, pp. 233-234).

${ }^{6}$ Reglamento de instrucciones para el servicio de las comisarías policiales en la campaña, 1857. Segunda caja, documento núm. 081. Archivo Histórico Municipal de Tandil (Анмт), Tandil, Argentina. 
de paz al retirarles funciones para atribuirlas a los comisarios que serían designados por el gobierno provincial. Desde los inicios en la década de 1820, el nombramiento de los jueces de paz era una prerrogativa del gobernador. Sin embargo, la elección se realizaba a partir de una terna propuesta por el magistrado saliente que, generalmente, era el producto de las tensiones y acuerdos al interior de cada comunidad. La legitimidad de estos jueces era esencial para garantizar el orden en cada partido y el cumplimiento de las normativas del gobierno. Al mismo tiempo, el consenso generado les permitía cierto margen de autonomía para mediar en el acatamiento de las normas, especialmente en espacios como el de la campaña bonaerense donde no había una entramado de autoridades (Garavaglia, 1999).

El Reglamento también estableció que la partida de los juzgados de paz quedaba conformada por cuatro integrantes, el resto -aproximadamente ocho personas, según el caso- pasaban a depender del comisario quien debía reunir un grupo de entre diez y quince hombres. Al mismo tiempo, el presupuesto de los juzgados de paz se reducía considerablemente para sostener el funcionamiento de las comisarías. Los comisarios quedaron bajo el mando de los prefectos pero también de los jueces de paz para las diligencias judiciales. Sus incumbencias y atribuciones incluían: recorrer los partidos a su cargo, prestar atención "muy especial" a la persecución y aprensión de "cuatreros, [...] desertores [...] y mal entretenidos". En esta normativa, se establecieron los pasos a seguir en la elaboración de sumarios en casos de delitos y se ordenaba la observación de las instrucciones que enviaran los jueces de primera instancia. Por otro lado, estaban encargados de la recolección de los caballos patrios y su conservación, dado que eran fundamentales para las fuerzas militares. Entre las funciones esenciales se encontraban la conservación del orden en reuniones y diversiones públicas, acudir y auxiliar en ocasión de peligros, hacer ejecutar y observar las disposiciones dictadas acerca de juegos prohibidos, la caza de animales y el uso de armas, principalmente en los pueblos y en aquellas pulperías que estaban aisladas o distantes.

La instauración de las comisarías fue seguida del de las prefecturas por medio de la sanción de una nueva ley. ${ }^{7}$ El propósito era establecer una nueva jurisdicción sobre las ya existentes para facilitar el control territorial por parte del gobierno. Cada prefectura estaba compuesta por entre cinco

${ }^{7}$ Ley $\mathrm{N}^{\circ} 156$. Prefecturas departamentales y demarcación territorial de los partidos (Ketzelman y Souza, 1931, t. I, pp. 262-265). 
y diez partidos a cargo de un prefecto que debía residir en la cabecera de acuerdo a las designaciones realizadas por el poder ejecutivo provincial. ${ }^{8}$ La conformación de las jurisdicciones a cargo de los prefectos fue similar a la estudiada por Romana Falcón (2015). Sin embargo, a diferencia del caso mexicano los cabildos o ayuntamientos se disolvieron en 1821 y las municipalidades no fueron creadas hasta 1854. Como se mencionó, el gobierno local quedó en manos de una institución que no era estrictamente unipersonal, como los juzgados de paz, pero donde el juez detentaba buena parte del poder. Esta situación no se modificó con la creación de las municipalidades dado que el cargo de presidente de la misma también era desempeñado por el magistrado local. En el mapa 1 se muestra la conformación de las prefecturas y los partidos que las integraban.

Los límites de las jurisdicciones son estimativos dado que entonces no estaban claramente definidos. ${ }^{9}$ Una situación similar se planteó con la llamada línea de frontera -así denominada en el mapa original- que estaba lejos de representar la división entre el espacio controlado por las autoridades de la provincia y aquel dominado por las parcialidades indígenas. Diversos estudios mostraron que se trató de un espacio de convivencia entre indígenas, criollos e inmigrantes. Una coexistencia donde el conflicto en diversas manifestaciones no estuvo ausente, pero que nunca implicó el fin de las relaciones personales, políticas y comerciales establecidas y consolidadas en dicho ámbito (Yangilevich, 2009). La escasa precisión de los límites entre jurisdicciones corría paralela con el estado de provisionalidad que atravesaba diferentes iniciativas institucionales. Por ello, en la nueva ley de prefecturas se sostuvo que los departamentos se formarían "por ahora" con los partidos existentes. Uno de los aspectos esenciales de la disposición residía en el nom-

${ }^{8}$ La $1^{\text {a }}$ prefectura se conformó con los partidos de San José de Flores, Belgrano, San Isidro, San Fernando, Las Conchas, Morón y Matanza. La $2^{a}$ por de Giles, Luján, Carmen de Areco, San Antonio de Areco, Baradero, Zárate, Pilar y Exaltación de la Cruz. La $3^{\text {a }}$ por San Pedro, San Nicolás, Junín, Rojas, Pergamino, Arrecifes y Salto. La $4^{a}$ por Mercedes, Navarro, Lobos, Chivilcoy, Bragado y 25 de Mayo. La $5^{\text {a }}$ por Cañuelas, Monte, Las Flores, Saladillo, Tapalqué y Azul. La $6^{\text {a }}$ por Tandil, Pila, Mar Chiquita y Lobería. La $7^{\text {a }}$ por Dolores, Vecino, Tuyú, Tordillo y Ajó. Por último, la $8^{\mathrm{a}}$ por Ranchos, Chascomús, Magdalena, Ensenada, Quilmes, Barracas al Sud y San Vicente.

${ }^{9}$ La ley que reorganizó la justicia letrada en 1856 estableció que el Departamento del Sud se integraría con los partidos existentes al sur de Ranchos, sin mencionarlos debido a que no existía certeza sobre las jurisdicciones existentes. Ley del 24 de octubre de 1856 "Se divide la jurisdicción de los Jueces del crimen en la Campaña en tres Departamentos” (Prado y Rojas, 1878, t. v, pp. 266-267). 
Mapa 1. Prefecturas y comisarías de campaña (1857-1859)

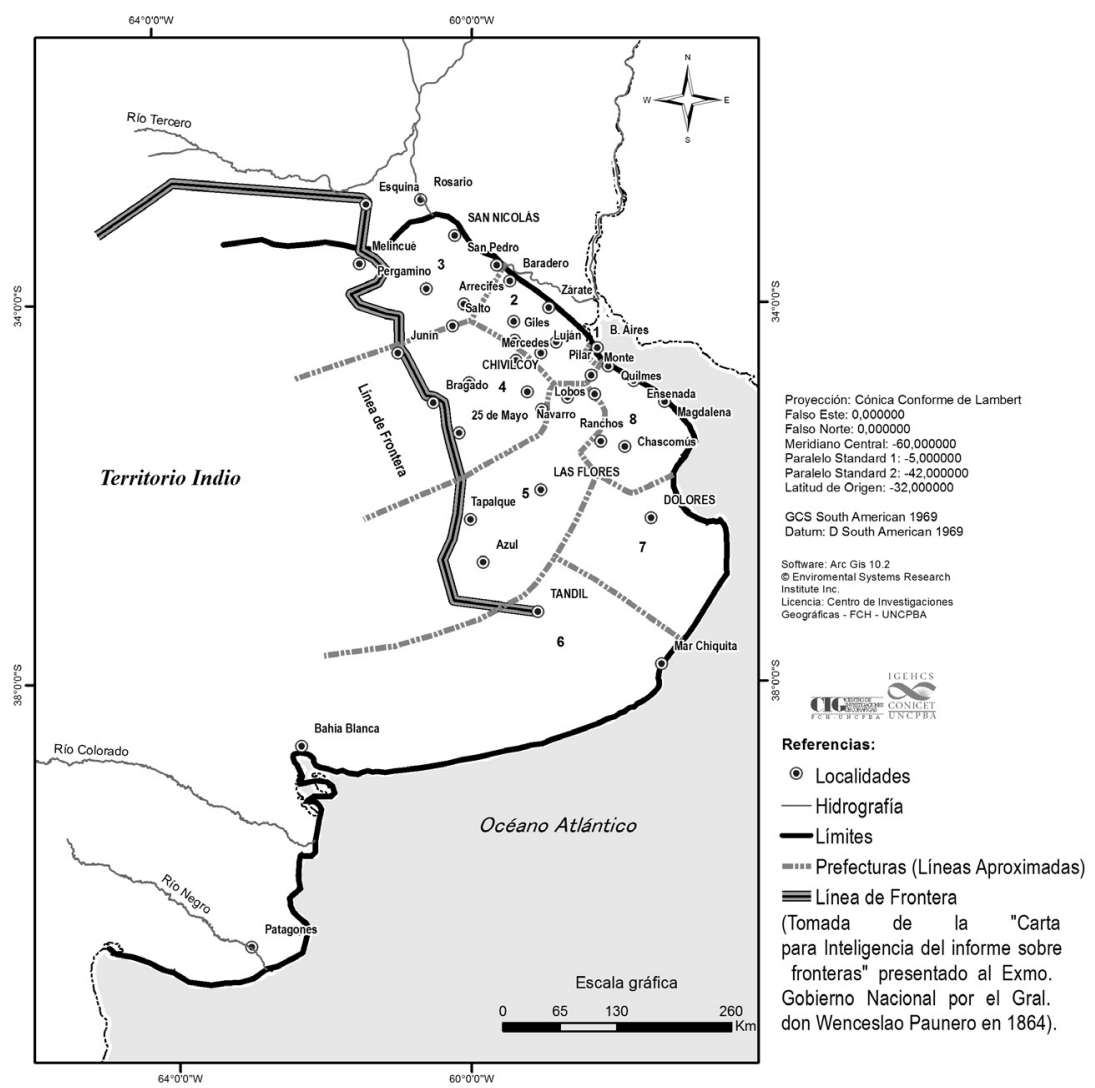

Fuente: elaboración propia a partir del mapa incluido en el texto de Benito Díaz (1959).

bramiento de los prefectos a cargo del gobierno provincial. La designación se realizó en hombres considerados como leales. Así se procuraba establecer una autoridad que pudiera sobreponerse a la de los jueces de paz.

En síntesis, fueron considerados jefes de la administración de cada departamento y "agente inmediato y subordinado del Poder Ejecutivo en los ramos de gobernación, hacienda y guerra". Además debía mantener "policialmente la seguridad y el orden público" aunque la normativa agregaba que el 
prefecto no mandaba "fuerza armada" sin previa autorización del gobierno. En caso de necesidad, los prefectos podían reunir a la Guardia Nacional de los partidos a su cargo pero debían ponerla a las órdenes de sus jefes respectivos. ${ }^{10}$ En este punto, los prefectos bonaerenses se diferenciaron de sus pares santafesinos y mexicanos. Ambos mantuvieron una incidencia directa en la convocatoria de quiénes debían acudir al servicio de las armas (Bonaudo, 2008, pp. 268-269) o el "contingente de sangre" requerido por las autoridades federales (Vilchis, 2012, p. 88). La comparación permite sugerir que la imposibilidad de ejercer mando sobre las fuerzas militares fue un factor importante en las condiciones en las que los prefectos bonaerenses ejercieron su mando.

La normativa que procuró recortar las prerrogativas de los jueces de paz dejó en sus manos todo lo referido a la administración de baja justicia. Esta fue una de las facultades centrales y fundamento del poder que estos agentes acumularon durante el siglo decimonónico. Entre las disposiciones, se incluyó una que resultaría importante para la relación entre los prefectos y las corporaciones municipales. Cada prefecto debía observar si las municipalidades atendían "debidamente a sus objetos y obligaciones, sin ingerirse por eso en su dirección ni operaciones, limitándose a instruir de todo al gobierno". Las diferentes disposiciones no dejaban lugar a dudas sobre el propósito de esta nueva normativa. En este punto, el propósito de los papeles de estos funcionarios se asemeja a lo que demandaban las autoridades centrales de sus pares de México y Colombia (Falcón, 2015; Vélez, 2012). Los prefectos debían ser no sólo los delegados del gobierno provincial en el interior de la campaña sino, fundamentalmente, sus ojos y oídos. El ministro de Gobierno y Relaciones Exteriores, José Barros Pazos, lo expresó durante el debate de la ley. Cada prefecto tenía por objeto primordial establecer centros locales de administración en la campaña para que el poder ejecutivo pudiera "hacerse sentir de una manera ventajosa” en el ámbito rural (Díaz, 1959, p. 45).

Como se señaló, la delimitación territorial fue un problema importante dado que las autoridades admitieron que la división de los partidos era

\footnotetext{
${ }^{10}$ La convocatoria de los guardias nacionales era realizada por los comandantes al prefecto y llevada a cabo por los comisarios y alcaldes. Libro copiador de correspondencia con las autoridades que se dirigen a la sección $13^{\mathrm{a}}$ del Tandil. Documento núm. 216, 1857, segunda caja, f. 91. Анмт, Tandil, Argentina.
} 
"irregular", ${ }_{11}^{\text {y }}$ ello podía provocar disputas entre los prefectos de las distintas jurisdicciones. A pesar de las dificultades, el gobernador Alsina decidió avanzar con su proyecto. Por medio de un decreto designó a los prefectos de cada departamento. En el $1^{\circ}$ se designó a Juan Dillon, en el $2^{\circ}$ a José Ramón Oyuela, en el $3^{\circ}$ a Álvaro Barros, en el $4^{\circ}$ a Federico Suárez, en el $5^{\circ}$ a Antonio Rodríguez, en el $6^{\circ}$ a Juan Elguera, en el $7^{\circ}$ a Fernando Otamendi y en el $8^{\circ}$ a Martín de la Serna.

De manera paralela, comenzaron a organizarse las municipalidades en el territorio provincial. Si bien la ley respectiva fue aprobada en 1854, el enfrentamiento entre la provincia y la Confederación así como los ataques indígenas tornaron inviable el establecimiento de estas instituciones con anterioridad. Hacia 1857 se había logrado una relativa -y siempre frágil-calma sostenida por la continuidad en la entrega de animales y otros obsequios a los grupos indígenas. ${ }^{12} \mathrm{Al}$ mismo tiempo, el ministro de Guerra y Marina, general Matías Zapiola, dispuso la organización de la Guardia Nacional, la división de la campaña en 17 regimientos y la creación de cuatro unidades de guardias nacionales activas y una pasiva (Whalter, 1947). A través de la puesta en funcionamiento de diferentes instituciones, Alsina buscó fortalecer la autoridad del gobierno en el espacio de la campaña bonaerense que parecía diluirse en la medida en que aumentaba la distancia desde la ciudad puerto. ${ }^{13}$

${ }^{11}$ Documento núm. 164, 1857. Decreto oficial sobre las prefecturas de campaña. AHмT, Tandil, Argentina.

${ }^{12}$ Los ataques indígenas -generalmente a una escala sustancialmente menor que la desplegada en 1855- persistieron hasta entrada la década de 1870.

${ }^{13}$ Las reformas descritas no fueron las únicas impulsadas por Alsina. En 1857 propició la organización del Superior Tribunal de Justicia, la renovación del Departamento Topográfico, la resolución de cuestiones pendientes sobre dominios de tierras fiscales e impulsó la ley que aprobaba el presupuesto destinado a la confección de los códigos. En síntesis, Alsina desplegó desde lo normativo un proyecto de gobierno centralizado que se vio frustrado rápidamente debido a su salida del gobierno. Sin embargo, continuó siendo un actor central de la vida política de la provincia de Buenos Aires y procuró consolidar algunos de sus proyectos. Así, en 1865 redactó el Código Rural de la Provincia de Buenos Aires, luego adoptado por otros estados provinciales, donde procuró establecer, una vez más, limitaciones al poder de los jueces de paz. 


\section{PREFECTOS, COMISARIOS, JUECES DE PAZ, COMANDANTES Y VECINOS. UNA CONVIVENCIA COMPLEJA}

Luego de la sanción de las leyes sobre comisarías y prefecturas, los funcionarios designados se trasladaron a sus jurisdicciones. Los registros documentales que generaron a partir de una copiosa correspondencia dieron cuenta de la multiplicidad de contrariedades que enfrentaron en el desempeño de sus actividades. Por un lado, la documentación existente muestra la escasez presupuestaria que se manifestó en varios aspectos. En agosto de 1857 Lisandro Medina -comisario de la $5^{a}$ sección de Zárate-le envió una nota al jefe del Departamento General de Policía de la provincia Emilio Castro para "suplicarle" que le enviara "con la brevedad que sea posible" los útiles de oficina y el escritorio que necesitaba para el desempeño de sus funciones. ${ }^{14}$ En diciembre del mismo año, Fernando Otamendi, prefecto del $7^{\circ}$ departamento -con sede en Dolores-, envió una nota en el mismo sentido. Sin embargo, la escasez de los elementos de oficina y mobiliario no fue el mayor inconveniente que afrontaron comisarios y prefectos cuando pretendieron tomar posesión de sus cargos.

En varios casos, en los pueblos cabecera no había construcciones adecuadas donde instalar las comisarías. En el mes de agosto de 1858 el comisario de Bragado, Manuel Fernández, le hizo saber a Castro el mal estado de los caminos, el "casi" completo abandono de las postas por la falta de caballos y la "mucha dificultad" para hallar una casa donde ubicar la comisaría. De manera simultánea, León Gutiérrez, comisario de Pila, relató la imposibilidad de alcanzar "la realización de tan indispensable objeto [...] a pesar de haber practicado todas las diligencias posibles". Según explicaba, los establecimientos rurales apenas contaban con la comodidad necesaria para sus habitantes con la excepción de la estancia de la familia Anchorena, una de las más importantes de la provincia. A pesar de la "capacidad y conveniencia" de esa posesión, nada se podía hacer sin que los dueños dieran las instrucciones correspondientes, o al menos eso era lo que sostenía el encargado con el que Gutiérrez sostuvo un enfrentamiento persistente ${ }^{15}$ (Yangilevich, 2010). A

${ }^{14}$ Sala X, 20-2-8. Archivo General de la Nación (AGN), Argentina. Salvo referencia en contrario la documentación fue extraída del legajo citado.

${ }^{15}$ En enero de 1858 Gutiérrez informó al prefecto Elguera sobre una persecución en terrenos de los Anchorena aclarando que dio cuenta de sus acciones a don Nicolás, jefe de la mencionada familia. Caja 1, documento núm. 143, 1858. Aнмт, Tandil, Argentina. Esta 
pesar de la oposición del capataz, logró instalarse en la propiedad de Anchorena aunque sostuvo que seguía buscando otra casa para poder desempeñar su cargo "con amplitud".

A los contratiempos que implicaba no contar con ciertas comodidades que en la campaña parecían no abundar, se sumaron otras carencias. La falta de hombres y caballos para el servicio generó limitaciones tanto o más relevantes. Como se mencionó, los individuos que debían formar la partida de la comisaría eran los mismos que hasta entonces se desempeñaban bajo las órdenes de los jueces de paz. Sin embargo, tales traspasos no fueron sencillos y los comisarios se lo hicieron saber a sus superiores. El mencionado Gutiérrez en una de sus notas relató que en el juzgado se encontró con el "inconveniente" de que los siete hombres sobrantes de las partidas se negaron a pasar a la comisaría porque estaban en comisión bajo el mando del juez de paz. ${ }^{16} \mathrm{En}$ su opinión, este los retenía para su servicio y por tanto, no contaba con ningún subalterno para realizar las actividades previstas.

A las dificultades para el traspaso de los hombres prevista en la ley se agregaron otras complicaciones para reclutar individuos capaces para cumplir con el servicio en las comisarías. El comisario Medina explicó las causas en una nota dirigida a las autoridades:

no se pueden encontrar los hombres morales y aptos para las partidas de la comisaría que quieran entrar libremente a ella al saber que no se les da el ran$c h o^{17}$ pues comprenden que teniendo que desempeñar un servicio activo no tienen tiempo de ocuparse en otros trabajos cuyos productos les suministran su manutención porque con los $\$ 200$ asignados por el Superior Gobierno no es posible que actualmente viva un hombre.

Agregó que encontró algunos individuos que no estaban "llenos de aptitudes" a quienes debió prometerles su intermediación ante las autoridades

\footnotetext{
familia desplegó una gran capacidad para acumular riqueza y se mantuvo como una de las principales integrantes de la elite económica y política argentina (Hora, 2012).

${ }^{16}$ Nota del comisario de la sección $12^{a}$ de Pila León Gutiérrez al jefe del Departamento General de Policía Emilio Castro, 1 de noviembre de 1857. Caja 1, documento núm. 589. Анмт, Tandil, Argentina.

${ }^{17}$ El rancho consistía en la entrega de alimentos y bebidas necesarios para la manutención cotidiana de los hombres que desempeñaban diversas tareas en las filas militares o establecimientos productivos.
} 
para que se les pasara "rancho" y así convencerlos de sumarse a la partida. León Gutiérrez se expresó en términos similares. En una nota enviada a las autoridades provinciales sostuvo que para realizar un servicio tenía que "sostener la partida y proveer los artículos necesarios por su cuenta [...] considerando la carestía que se nota en estos destinos en todo lo que es de absoluta precisión [...] y la imposibilidad de que puedan subsistir con los $200 \$$ que se asigna a cada individuo por todo haber". ${ }^{18}$ Además, en coincidencia con lo expresado por Medina, afirmó que no podía encontrar hombres que quisieran servir sin que además del sueldo se les pagase la manutención. En ambas notas, los argumentos sobre lo escasa de la paga se repiten con palabras similares.

Tales demandas no eran novedosas en el ámbito de la campaña. Jorge Gelman (2009) mostró que hacia la primera mitad del siglo xIx los peones empleados en las estancias del gobernador Rosas presionaron con relativo éxito para la obtención de mejores condiciones de trabajo y salarios. Los "vicios" o "rancho" formaban una parte vital del pago para aquellos peones y en el mismo sentido se expresaron los hombres que se negaban a ingresar a la policía por una paga considerada insuficiente. En estos casos, los comisarios debieron ceder ante la presión conviniendo pedir un adicional para el "rancho" o asumiendo los costos para el mantenimiento de la tropa. La remuneración percibida era considerada insuficiente y por ello las dificultades para formar las partidas debieron multiplicarse.$^{19}$ Ello puede explicar el pedido de varios comisarios a las autoridades para hacerles saber la imposibilidad de mantener a sus subalternos con el sueldo asignado. El gobierno decidió agregar un adicional de $\$ 50$ para cada hombre. Esta resolución no pareció ser del agrado de Gutiérrez quien sostuvo que la misma podía ser beneficiosa donde los dueños de animales vacunos vendían o incluso auxiliaban con la carne. ${ }^{20}$

${ }^{18}$ Subrayado en el original. Nota del comisario de la sección $12^{\text {a }}$ de Pila, León Gutiérrez a Emilio Castro, 25 de agosto de 1857. Caja 2, documento núm. 457, 1857. Анмт, Tandil, Argentina.

${ }^{19}$ A lo mencionado, cabe agregar el problema de la deserción, que debió ser elevada. A modo ilustrativo cabe mencionar la nota enviada por Wenceslao Paunero al prefecto Elguera para darle aviso que en su marcha hacia Bahía Blanca había sufrido la "pequeña pero sensible pérdida de siete bajas en la tropa, cinco desertores de Húsares y dos muertos”. Caja 2, documento núm. 308, 1857. Анмт, Tandil, Argentina.

${ }^{20}$ Por su parte, Severo Ezpeleta, comisario de Tandil, acusó recibo a Emilio Castro de la disposición de pedir auxilio de hombres y caballos a los hacendados para aumentar las partidas que debían incorporarse al comandante militar para la aprensión de los grupos de vagos que producían "todo tipo de desórdenes". Nota del 3 de octubre de 1857. Caja 2, documento núm. 506, 1857. Анмт, Tandil, Argentina. 
Según explicaba, ese no era su caso en el partido de Pila. En el establecimiento de los Anchorena, que ocupaba la tercera parte de esa jurisdicción, el capataz Letamendi no le daba la carne e incluso se negaba a vendérsela. Por eso, pidió autorización para tomar por su cuenta ocho reses que era lo que necesitaban sus hombres por mes "con arreglo a lo que es de práctica en la frontera". La sucesión de conflictos entre este comisario y Letamendi llegó a oídos del gobierno. El ministro Barros Pazos consideró que la conducta del comisario había sido abusiva e irregular mientras que a este último lo describió como un ciudadano honrado (Yangilevich, 2010). Las autoridades buscaron establecer un equilibrio que se reveló frágil entre sus allegados y los vecinos notables de la campaña. En el sentido señalado por Vélez Rendón en su estudio del cantón del norte colombiano, las tensiones respondían a una puja entre los intentos de las autoridades por consolidar su poder y las resistencias que ejercían diversas personas con intereses e influencia social, política y económica, aunque no detentaran cargos (Yangilevich, 2012, p. 60).

Un problema adicional a los mencionados era la escasez de caballos, que resultaban indispensables para movilizarse en la campaña. Varios comisarios y prefectos trasmitieron a las autoridades su preocupación por este motivo. El prefecto del $3^{\circ}$ departamento, Wenceslao Paunero, pidió autorización para comprar entre 35 y 40 con los que montar a los hombres que integraban el escuadrón bajo su mando. ${ }^{21}$ En su opinión no era útil que dicha fuerza estuviera "en estado de disciplina" si no contaba con la movilidad necesaria. El pedido fue aceptado por las autoridades con la recomendación de que los animales fueran mansos, sanos y de buenas carnes. La persistente carencia de ganado equino generó diferentes conflictos entre vecinos y autoridades que se explican en la dinámica más amplia referida más arriba. En 1859 fueron robadas dos tropillas de caballos a don Venancio Insaurralde, vecino del Arroyo del Medio, paraje lindante con la provincia de Santa Fe. Junto a otros hombres decidieron pasar a esta jurisdicción para recuperarlos. Paunero elogió el valor demostrado pero recriminó que ingresaran a otra provincia sin autorización y "a mano armada" aunque fuera para recuperar lo robado. ${ }^{22}$ La acción directa encabezada por Insaurralde pareció mostrar la

${ }^{21}$ Nota del prefecto del $3^{\circ}$ departamento Wenceslao Paunero al minisitro de Gobierno, 15 de enero de 1859. Caja 1, documento núm. 25, 1959. Анмт, Tandil, Argentina.

${ }^{22}$ Nota del prefecto del $3^{\circ}$ departamento Wenceslao Paunero al capitán encargado de la partida celadora del Arroyo del Medio, 17 de enero de 1859. Caja 1, documento núm. 32. Анмт, Tandil, Argentina. 
falta de certidumbre en la capacidad de las autoridades para ejercer su potestad y recobrar los animales.

Los conflictos por la escasez de animales se generaron, también, entre las propias autoridades. En septiembre y octubre de 1859 el capitán Sindolfo Pagola -bajo las órdenes del coronel Ignacio Rivas-se llevó todos los caballos que encontró en el partido de Las Flores. Un grupo de vecinos se presentó ante el prefecto Manuel Paz quejándose por el arreo de sus caballadas sin que Pagola diera aviso ni entregara los recibos correspondientes. Lo mismo le sucedió a Federico Terrero, quien comunicó a Paz que las tres postas a su cargo no podían funcionar por la falta de animales, todos arreados por el mismo capitán. ${ }^{23}$ La intervención del prefecto no se hizo esperar, envió una nota a Pagola donde lo hacía responsable de los graves abusos realizados bajo el amparo de una comisión oficial. También le hizo saber "todo el descrédito que [...] esta[ba] haciendo recaer sobre el Gobno., apartándose completamente de las órdenes superiores". A ello agregaba que sabía por el coronel Rivas que las instrucciones consistían en sacar sólo los caballos que estuvieran en buen estado y así, evitar perjuicios en un doble sentido. Por un lado, para no pagar por caballos cansados que no serían útiles para el transporte. Y por otro, porque esos mismos animales dejados en sus querencias y restablecidos podían estar aptos para servir al Estado. De acuerdo con las palabras del prefecto, Pagola no podía desconocer los daños causados a las autoridades provinciales $y$, fundamentalmente, al papel de Paz como "jefe del departamento y agente inmediato del gobierno encargado de hacer cumplir las órdenes". Dado que el prefecto no recibió respuesta a sus reclamos envió una copia de todo lo actuado a Pastor Obligado, ministro de Guerra y Marina. En su misiva sostuvo que le era "sensible" afirmar que de las cuatro notas enviadas a Pagola ninguna fue contestada probando de ese modo la indiferencia ante los reclamos de la prefectura por parte de quien era un empleado del gobierno. A pesar del celo que mostró en el desempeño del cargo, Paz no obtuvo respuestas por parte de las autoridades provinciales.

La presencia de los prefectos y comisarios que se multiplicaron en los diversos partidos de la campaña causaron recelo entre los jueces de paz, dado que las nuevas autoridades buscaron restarles partes importantes de sus funciones y potestades así como imponer funcionarios que mostraran una

${ }^{23}$ Nota del prefecto del $5^{\circ}$ departamento Manuel Paz al ministro de Gobierno, 12 de octubre de 1859. Caja 2, documento núm. 614. 1859. Aнмт, Tandil, Argentina. 
mayor lealtad al gobierno provincial. Los asuntos locales eran conocidos con mayor detalle por los comisarios que controlaban -o al menos eso se esperaba de ellos- un territorio más reducido que los prefectos. La percepción de que estos debían actuar como los ojos y oídos del gobierno queda claramente ejemplificada en la nota enviada por el comisario de Tandil, Severo Ezpeleta, a Emilio Castro. En la misma se refirió a la terna enviada por la municipalidad para la elección del juez de paz para el año $1858 .{ }^{24}$ En ella se proponía en primer término a José Buteler, en segundo lugar a Francisco Rodríguez y, por último, a Manuel Casado. ${ }^{25}$ Según el comisario, este último no había inspirado la confianza de la municipalidad por ser "amigo" de las autoridades provinciales, pertenecer al Club Libertad y poseer "cualidades morales y honradez" de las que carecían los otros miembros de la terna. Para Ezpeleta, estas características lo habrían ubicado en el último lugar. Aun cuando un caso no habilita a arribar a conclusiones firmes, es posible pensar que la designación de los jueces de paz fue un punto de tensión entre las municipalidades y el gobierno provincial, como lo deja entrever este caso puntual. Eso quizás explique la decisión adoptada en septiembre de 1858 a partir de la cual los jueces de paz serían designados por el poder ejecutivo provincial "sin sujetarse a las ternas de la municipalidad" ${ }^{26}$ En la misma nota el comisario informó que los periódicos que circulaban en Tandil eran opositores. Aun así, sostuvo que en la generalidad del vecindario existía un "buen sentimiento" hacia el gobierno provincial, quizás para mostrar una situación más ventajosa que no se traducía en sus palabras.

Por otro lado, surgieron disputas por las funciones, atribuciones e incluso las jurisdicciones entre las diferentes autoridades que se superponían sobre un mismo territorio. Una parte de los conflictos se generó en torno a la revisión de los cueros que implicaba examinar el origen de los que entraban y salían de cada partido. Una de las facultades asociadas al escrutinio de esos frutos consistía en la posibilidad de imponer multas cuando se detectaban

${ }^{24}$ Nota del comisario de la sección $13^{a}$ de Tandil Severo Ezpeleta al jefe del Departamento de Policía Emilio Castro, 7 de octubre de 1857. Caja 2, documento núm. 347. 1857. Анмт, Tandil, Argentina.

${ }^{25}$ Es posible que Elguera confundiera el nombre de pila de Casado, ya que en agosto de 1858 quien aparece como juez de paz de Tandil es Juan Casado. Caja 2, documento núm. 284. 1858. Анмт, Tandil, Argentina.

${ }^{26}$ Ley 225, Dependencia de los cuerpos de serenos, padrones de extranjero y nombramientos de los jueces de paz (Ketzelman y Souza, 1931, t. I, pp. 436-437). La medida quedó sin efecto luego del fin del gobierno de Alsina. 
irregularidades. Con un presupuesto escaso la posibilidad de contar con ingreso extra era relevante para las diversas autoridades debido a que lo recaudado quedaba en la comunidad. Quizás por ello, varios comisarios consultaron al jefe de policía, Emilio Castro, si entre sus atribuciones se encontraba la de revisar las marcas de los cueros que eran extraídos de sus jurisdicciones. Según Pedro José Machado, comisario de Dolores, circulaban cueros robados no revisados que los comerciantes procuraban legalizar pidiendo certificados que no se correspondían con las marcas asentadas. ${ }^{27}$ Aunque no delegaba directamente la responsabilidad en ninguna otra autoridad, es posible que se refiriera al juez de paz local. No todos los comisarios pretendieron controlar la comercialización de los cueros. Julián Flores, comisario de Azul, encomendó a los alcaldes la vigilancia de la comercialización de esos frutos para evitar los fraudes, que parecieron ser frecuentes. ${ }^{28}$

Una parte importante de las consultas elevadas al gobierno provincial procuraba delimitar las atribuciones entre comisarios y magistrados locales. El comisario del partido de Rojas, Cecilio Echeverría, planteó sus dudas y las de algunos jueces de paz sobre las disposiciones policiales en relación con la facultad de los pulperos de vender licores en botellas que se bebían en público. Echeverría sostuvo que esa práctica generaba escándalos en un espacio que era, además, un destacamento militar, y donde ese abuso atentaba contra la disciplina de las tropas y la moral pública. Otro punto de tensión se generó a partir de la custodia de los individuos que eran detenidos debido a que implicaba destinar hombres en un contexto de escasez de brazos en las fuerzas militares. El mencionado coronel Machado presentó sus quejas sobre el juez de paz de Dolores que se negaba a aceptar detenidos en la cárcel pública del pueblo porque, al mismo tiempo, no enviaba vigilantes. Machado agregó que el juez de paz no había aportado a las fuerzas militares "ni uno solo de los (hombres) que tenía" al momento de organización de la comisaría. Agregó que logró completar la partida debido a las incorporaciones que realizó por su propia cuenta.

${ }^{27}$ Nota del comisario de la sección $17^{\mathrm{a}}$ al jefe del Departamento de Policía Emilio Castro, 28 de septiembre de 1857. Sala X, 27-3-3. AGN, Argentina. Las notas referidas en este apartado fueron extraídas del expediente con la numeración mencionada, salvo indicación en contrario.

${ }^{28}$ Nota del comisario de la sección $11^{a}$ al jefe del Departamento de Policía Emilio Castro, 17 de octubre de 1857. 
Otro tipo de fricciones surgió debido a la detención de sujetos que contaban con una red de relaciones que podía brindarles cierta protección. En otro lugar, relatamos la reacción de Machado, quien amenazó a un alcalde de Tandil con "darle unas patadas" si volvía a detener a algunos de los hombres que pertenecían al regimiento que comandaba (Yangilevich, 2006). En otra ocasión, este coronel se dirigió a Juan Elguera, prefecto del $7^{\circ}$ departamento, para pedir la libertad de varios individuos que habían sido detenidos por el comisario de Mar Chiquita y enviados presos a Tandil. En su opinión, tal proceder no fue el correcto dado que esos hombres pertenecían a su regimiento y "habían cumplido con su deber" actuando del modo en que lo hicieron. En otras ocasiones, aunque la fricción no llegaba a las amenazas quedaba claro que el peso de los vínculos sociales inclinaba la balanza y determinaba, en este caso, la libertad del individuo involucrado. El comisario de Chascomús, Valeriano Barreda, comunicó al jefe de policía Castro que detuvo a un desertor llamado Justo Casado, más conocido como Maragato. ${ }^{29}$ Inmediatamente se presentaron ante él José Leonzo, juez de paz, y otros "vecinos respetables". Estos argumentaron que Casado había sido destinado a las armas dos años atrás, que se había fugado pero que posteriormente se presentó y fue indultado por pedido del juez local Vicente Aristegui. En contra de su voluntad el comisario se vio obligado a liberarlo.

En ocasiones, además de los vínculos que podían proteger a alguien señalado como delincuente, las reglamentaciones actuaron de freno al accionar de las nuevas autoridades. Según explicó Rufino Martínez, comisario de Las Flores, en una nota a Castro, ${ }^{30}$ había tenido noticias de que dos ladrones conocidos circulaban por su jurisdicción donde contaban con algunas amistades. Se dirigió a estas "casas sospechosas" sin obtener resultado favorable debido, según su opinión, a que el "formulario" no le permitía inspeccionar viviendas o negocios sin contar con la autorización del juez de paz. ${ }^{31}$ Martínez explicó que el magistrado se encontraba a más de quince leguas, por lo que hubiera sido necesario pedir su consentimiento y volver. Resolvió continuar dado que eso hubiera demandado dos o tres días de marcha, tiempo suficien-

\footnotetext{
${ }^{29}$ Nota del comisario de la sección $18^{a}$ Valeriano Barreda al jefe del Departamento de Policía Emilio Castro, 10 de septiembre de 1857.

${ }^{30}$ Nota del comisario de la sección $10^{\mathrm{a}}$ Las Flores Rufino Martínez al jefe del Departamento de Policía Emilio Castro, 24 de octubre de 1857.

${ }^{31}$ El comisario hace referencia al Reglamento e Instrucciones para el Funcionamiento de las Comisarías Policiales en Campaña, aprobado el 15 de julio de 1857.
} 
te para que los sospechosos huyeran. En la misma nota, el comisario informó sobre un homicidio ocurrido en Las Flores para el que procuró garantizar los procedimientos y allanar los "entorpecimientos" que se presentaron. El motivo de su queja era la negativa del cirujano Manuel Ocanto a entregar el certificado del reconocimiento de las heridas correspondiente mientras no se le pagase. De ese modo, el proceso quedaría inconcluso dado que tanto el certificado de entierro como la descripción de las heridas eran esenciales para probar el cuerpo del delito en los casos de homicidios. Por eso, consultó sobre la posibilidad de realizar él mismo el reconocimiento con el acompañamiento de dos testigos. Según explicó, en esos partidos de la campaña no había cirujano mientras que los "peritos o curanderos" se negaban a figurar en un reconocimiento médico debido a que el consejo de higiene pública les prohibía el ejercicio de esa facultad.

En otras ocasiones, los conflictos se generaban entre las autoridades de dos jurisdicciones colindantes por la invasión de alguna sobre el territorio de la otra. En noviembre de 1857 el comisario de Tandil, Severo Ezpeleta, recibió una nota de su par de Azul, Julián Flores, quejándose porque el alcalde Isidoro Trenco traspasó los límites y entró al partido bajo su jurisdicción donde detuvo a tres individuos. En su opinión Trenco debió pasar una nota para reclamar "los hombres [que fueran] perjudiciales" y dar a conocer las causas del arresto dado que, en ese caso, se trataba de vecinos. ${ }^{32}$ Lo que Flores censuraba no era la práctica habitual de entrar a otro partido sino la falta de aviso y autorización previos que implicaba el reconocimiento de la jurisdicción de otra autoridad. ${ }^{33}$

La correspondencia intercambiada entre comisarios, prefectos y las autoridades provinciales muestra las dificultades que los primeros encontraron para consolidar su autoridad. Sus permanencias en los diferentes puntos de la campaña parecieron estar signadas por la escasez de un presupuesto adecuado, de hombres que formaran las partidas, de armamento, de espacios apropiados donde establecer comisarías y prefecturas e incluso del

${ }^{32}$ Nota del comisario de Azul, Julián Flores al comisario de Tandil, Severo Ezpeleta, 21 de noviembre de 1857. Documento núm. 352, 1857. Анмт, Tandil, Argentina.

${ }^{33}$ En julio de 1857 el juez de paz de Tandil, González Cháves, daba aviso al alcalde del pueblo, de que había acordado con su par de Mar Chiquita para que comisiones de ambos partidos pudieran entrar a capturar hombres que se ocultaran en la jurisdicción vecina. Nota del juez de paz de Tandil al alcalde del pueblo, 24 de julio de 1857. Caja 2, documento núm. 91. 1857. анмт, Tandil, Argentina. 
mobiliario y los útiles de oficina. Los frecuentes intercambios daban cuenta además de la falta de conocimientos y de instrucciones precisas -o de su incapacidad para ponerles en práctica- en el desempeño de algunas funciones. Un punto común sobre el que varios de los comisarios solicitaron instrucciones fue sobre el procedimiento ante los daños producidos en los cultivos por diversos animales que comían los sembradíos. ${ }^{34}$ Entre ellos, Francisco Lozano, comisario de la Villa de Luján, se dirigió a Castro para pedirle criterios claros para resolver varias demandas que se le presentaron. Sostuvo que no podía expedirse al respecto debido a que carecía de "un perfecto conocimiento de las disposiciones". ${ }^{35}$ De manera paralela, pidió instrucciones especiales para evitar los abusos de los hacendados que pedían contratos para peones y capataces. Según Lozano, en esos momentos se estaba enrolando la Guardia Nacional y cuando eran convocados, los hombres presentaban las contratas como capataces y pedían la excepción cuando en realidad eran encargados de majadas pequeñas en los puestos de estancias. De esta manera, los dueños de establecimientos y capataces se aseguraban la afluencia de mano de obra en un contexto de persistente escasez de brazos y quienes debían enrolarse evitaban el servicio de las armas. En estas situaciones, también podían surgir disputas entre los prefectos y los jefes de la Guardia Nacional. El prefecto del $6^{\circ}$ departamento, Juan Elguera, en una nota al ministro de Guerra y Marina Pastor Obligado sostuvo que no sería extraño que hubieran ocurrido irregularidades en la convocatoria de los guardias nacionales debido a la urgencia con la que se impartieron las órdenes y apuntaba específicamente hacia el jefe del regimiento número 13. Aun cuando por ley los prefectos no tenían mando sobre fuerza armada, en diversas ocasiones se vieron involucrados en conflictos con los jefes militares. Los primeros solicitaron a los jefes de los regimientos de Guardias Nacionales las listas de los enrolados con el propósito de agilizar la aplicación de la ley de reclutamiento para el ejército, especialmente los artículos referidos a los destinados por vagancia. Si se leen estas demandas a la luz de las intervenciones de Machado cuando alguno de sus hombres fue detenido, es posible imaginar que la disputa generó diversas "cuestiones" entre los comandantes de los cuerpos y los delegados de las au-

\footnotetext{
${ }^{34}$ Las divisiones entre las propiedades se establecían por medio de mojones, cursos de agua o cercos vivos, en el mejor de los casos. El alambrado que dificultó el paso de animales y personas se generalizó a partir de 1870 .

${ }^{35}$ Nota del comisario de la sección $4{ }^{a}$ Villa de Luján, Francisco Lozano al jefe del Departamento de Policía Emilio Castro, 5 de septiembre de 1857. Sala X, 27-3-3. AGN, Argentina.
} 
toridades provinciales. El entonces asesor del gobierno, Dalmasio Vélez Sarsfield, sostuvo que antes de dirimir si estos últimos debían autorizar la convocatoria de los guardias nacionales en su jurisdicción, era necesario que el gobierno interviniera para que los prefectos no impidieran la reunión de las fuerzas militares de modo que el servicio público no se viera afectado y cada autoridad "supiera hasta donde alcanza(ba) su derecho" (Díaz, 1959, p. 58).

La reforma administrativa implementada entre 1857 y 1859 se inscribía en la formulación de un proyecto que proponía la construcción de un orden político republicano sobre cuya necesidad parecía haber acuerdo (Míguez, 2010). Sin embargo, en la práctica política la eficacia del sistema de poder construido sobre fundamentos clientelares $-\mathrm{y}$ sustentados en los jueces de paz-impidió por entonces que este quedara subordinado a las estructuras administrativas creadas por Alsina. En tal sentido, los prefectos y comisarios estaban inmersos en una lógica de prácticas políticas que resultaban contradictorias con aquellas que sustentaron la creación de esos mismos cargos. Asimismo, es necesario considerar que buena parte del territorio de la provincia constituía un espacio de frontera donde los mecanismos clientelares constituían el fundamento del orden social vigente. Durante la década de 1850 los representantes del Estado tuvieron una fuerte voluntad por invertir los términos de esta ecuación y buscaron expandir su control sobre la sociedad de la campaña. Alsina fue uno de los exponentes más lúcidos de esa iniciativa a partir de las instituciones que diseñó, algunas de las cuales lograron plasmarse. Este no fue el caso de las prefecturas de campaña de la provincia de Buenos Aires. El estudio sobre las condiciones de su implementación permitió, a su vez, analizar parte del complejo y contradictorio proceso de construcción estatal. Así como plantear las diferencias respecto a las dinámicas políticas de otras provincias argentinas donde los jefes políticos se constituyeron en figuras esenciales para la consolidación de las estructuras estatales.

\section{CONSIDERACIONES FINALES}

El propósito del trabajo consistió en el análisis de la organización y funcionamiento de las prefecturas de campaña durante el segundo gobierno de Valentín Alsina al frente de la provincia bonaerense. Este estudio buscó reflexionar sobre el proceso de construcción estatal incorporando las prácticas políticas cotidianas de actores alejados del centro político representado, 
en este caso, por Buenos Aires. El análisis se sirvió de indagaciones previas centradas en la construcción de la legitimidad política con posterioridad a los procesos revolucionarios de inicios del siglo XIX. Estos mostraron que la construcción estatal fue el resultado de un proceso extenso y signado por negociaciones cotidianas entre diversos actores. La investigación realizada se inserta en esta línea y procuró avanzar en el estudio de un periodo y un espacio no abordados por la literatura especializada. El análisis de diferentes corpus documentales permitió comprobar que una de las problemáticas centrales de las instituciones estatales para su consolidación en el espacio rural bonaerense fue la falta de una clara delimitación de papeles entre ellas y, por tanto, entre sus funcionarios.

Tal ambigüedad estuvo lejos de ser exclusiva de la coyuntura aquí analizada, por el contrario, atravesó buena parte del siglo xix. Esta fue una problemática central en el proceso de construcción estatal en diferentes espacios latinoamericanos. A la superposición de funciones debido a la creación de nuevos cargos se sumó la resistencia de las autoridades existentes a ceder una cuota del poder que detentaban. En el estudio realizado se comprobó que en estos años el problema se acentuó debido a la red de funcionarios que el gobierno de Alsina desplegó en la campaña. De manera similar a lo referido por Falcón para el caso mexicano (2015, pp. 169-170), los prefectos y comisarios, en contraposición a los jueces de paz y los comandantes militares, no eran originarios de los espacios donde debían ejercer sus funciones. Y en tal sentido, su capacidad de anclar su autoridad fue reducida dado que no contaban con la legitimidad -no exenta de cuestionamientos- que otorgaba una larga residencia en el pago o la continuidad al frente de un cargo o el mando de tropa. Contra ello no pudieron las sucesivas normativas que establecieron el recorte de prerrogativas de los poderes locales que descansaban en los jueces de paz. Las autoridades provinciales simplemente no pudieron hacerlas efectivas. A partir del análisis realizado es posible concluir que la construcción estatal en el espacio bonaerense fue un proceso arduo, nada lineal y contradictorio. Durante la década de 1850, de manera similar a lo ocurrido en la de 1820 , las autoridades provinciales tuvieron diversas dificultades para consolidar un poder que sólo de manera aparente provenía del nombramiento. En un contexto de debilidad de las instituciones estatales la potestad de establecer un orden determinado no residía en una autoridad específica. A diferencia de los prefectos y comisarios, los jueces de paz contaban con una larga existencia en la campaña desde su establecimiento en 1821. Su legiti- 
midad descansaba en los acuerdos cotidianos que debían establecer en los ámbitos locales. Alianzas y compromisos que involucraban a buena parte de los habitantes del espacio rural. Las dificultades para la puesta en acción de la reforma propiciada por Alsina parecieron descansar en una multiplicidad de carencias materiales e inmateriales. A la escasez de recursos monetarios se sumó la imposibilidad de delimitar tanto jurisdicciones como funciones, y por tanto, las autoridades no lograron generar el consenso necesario para construir obediencia entre la población de la campaña pero tampoco entre los funcionarios que hablaban -o debían hacerlo- en su nombre. Este estudio permitió abonar a la hipótesis que sostiene que la construcción estatal fue posible en el marco de la negociación cotidiana entre un amplio abanico de actores, incluidos aquellos ubicados en los márgenes sociales y espaciales.

\section{LISTA DE REFERENCIAS}

Barriera, D. (2002). Por el camino de la historia política: hacia una historia política configuracional. Secuencia, 53, 163-196. DoI: 10.18234/secuencia.v0i53.779

Barriera, D. (2009). Conjura de mancebos. Justicia, equipamiento político del territorio e identidades. Santa Fe del Río de la Plata, 1580. En D. Barriera (comp.), Justicias y fronteras. Estudios sobre historia de la justicia en el Río de la Plata. Siglos XVI-XIX (pp. 11-50). Murcia: Editum.

Bonaudo, M. (2003). Las elites santafecinas entre el control y las garantías: el espacio de la jefatura política. En H. Sabato y A. Lettieri (comps.), La vida política en la Argentina del siglo XIX. Armas, votos y voces (pp. 259-275). Buenos Aires: Fondo de Cultura Económica.

Bonaudo, M. (2008). Aires gaditanos en el mundo rioplatense. La experiencia de los jefes políticos y el juicio por jurados en tierras santafesinas (segunda mitad del siglo XIX). Revista de Indias, LXVIII(242), 255-280. DOI: 10.3989/revindias.2008. i2 242.642

Bragoni, B. y Míguez, E. (coords.), Un nuevo orden político. Provincias y Estado Nacional, 1852-1880 (pp. 79-97). Buenos Aires: Biblos.

Cucchi, L. (2014). La política como administración. El surgimiento y consolidación del Juarismo en la provincia de Córdoba, Argentina (1877-1883). Historia y Sociedad, 27, 71-99. Dor: 10.15446/hys.n27.44587

Delgado Aguilar, F. J. (2004). Orígenes e instalación del sistema de jefaturas políticas en México 1786-1824. Estudios de Historia Moderna y Contemporánea de México, 
28, 5-29. Recuperado de http://www.revistas.unam.mx/index.php/ehm/article/ view/3101

Díaz, B. (1959). La organización de prefecturas en la campaña de Buenos Aires durante el gobierno de Valentín Alsina. Trabajos y Comunicaciones, 8, 37-68.

Di Liscia, M. S. y Bohoslavsky, E. (coords.) (2005). Instituciones y formas de control social en América Latina 1840-1940. Una revisión. Buenos Aires: Prometeo Libros/ Universidad Nacional de General Sarmiento/Universidad Nacional de La Pampa.

Falcón, R. (1992). Jefes políticos y rebeliones campesinas: uso y abuso del poder en el Estado de México. En J. E. Rodríguez O. (ed.), Patterns of contention in Mexican history (pp. 243-273). Wilmington: SR Books.

Falcón, R. (1998). Los jefes políticos: eslabones de poder. En M. Miño Grijalva (ed.), Historia general del Estado de México. República restaurada y porfiriato (pp.99-121). México: Gobierno del Estado de México/El Colegio Mexiquense.

Falcón, R. (2007). Pueblos e indígenas en la difícil transición de la justicia. El Valle de México en la segunda mitad del siglo xIx. En R. Mandrini, A. Escobar Ohmstede y S. Ortelli (eds.), Sociedades en movimiento. Los pueblos indígenas de América Latina en el siglo XIX (pp. 81-97). Tandil: IEHs/FCH/UNCPBA.

Falcón, R. (2015). El jefe político. Un dominio negociado en el mundo rural del Estado de México, 1856-1911. México: El Colegio de México/El Colegio de Michoacán/Centro de Investigaciones y Estudios Superiores en Antropología Social.

Fradkin, R. (2009). ¿Misión imposible? La fugaz experiencia de los jueces letrados de Primera Instancia en la campaña de Buenos Aires (1822-1824). En D. Barriera (comp.), Justicias y fronteras. Estudios sobre historia de la justicia en el Río de la Plata. Siglos XVIXIX (pp. 144-165). Murcia: Editum.

Fradkin, R. (2014). Fuerzas militares y milicianas y configuración de un espacio fronterizo (1760-1820). En D. Barriera y R. Fradkin (coords.), Gobierno, justicias y milicias. La frontera entre Buenos Aires y Santa Fe, 1720-1830 (pp. 209-250). La Plata: FaHCE/UNLP.

Garavaglia, J. C. (1999). Poder, conflicto y relaciones sociales. El Río de la Plata, XVIII-XIX (pp. 89-121). Rosario: Homo Sapiens.

Gelman, J. C. (primer semestre, 2000). Crisis y reconstrucción del orden en la campaña de Buenos Aires. Estado y sociedad en la primera mitad del siglo xix. Boletín del Instituto de Historia Americana y Argentina "Dr. Emilio Ravignani", 21, 7-31.

Gelman, J. (2009). Rosas bajo fuego. Los franceses, Lavalle y la rebelión de los estancieros. Buenos Aires: Sudamericana.

Gilbert, J. y Nungent, D. (eds.) (1994). Everyday forms of State formation: Revolution and the negotiation of rule in modern Mexico. Durham: Duke University Press. 
Ketzelman, F. y Souza, R. (1931). Colección completa de leyes del estado y provincia de Buenos Aires desde 1854 a 1929 (t. I). Buenos Aires: Boucon y Cía.

Mecham, L. (1986). El jefe político en México. Secuencia, 4, 143-162. Dor: 10.18234/ secuencia.v0i04.131

Míguez, E. (2010). La frontera sur de Buenos Aires y la consolidación del Estado liberal, 1852-1880. En B. Bragoni y E. Míguez (coords.), Un nuevo orden político. Provincias y Estado Nacional, 1852-1880 (pp. 79-97). Buenos Aires: Biblos.

Palacios, G. (2007). Entre una "nueva historia política" y una "nueva historiografía" para la historia política de América Latina en el siglo xIx. En G. Palacios (coord.), Ensayos sobre la nueva historia política de América Latina, siglo XIx. México: Colmex.

Pavoni, N. (2000). Las jefaturas políticas y su incidencia en el clientelismo local: Córdoba 1870-1890. Cuadernos de Historia, 3, 113-167.

Peralta Ruiz, V. (2016). De prefectos a mandatarios de la nación. La violencia en la política peruana (1829-1836). Revista de Indias, LXXVI(266), 173-201. DoI: 10.3989/ revindias. 2016.006

Prado y Rojas, A. (1878). Leyes y decretos promulgados en la provincia de Buenos Aires desde 1810 a 1876. Buenos Aires: Imprenta El Mercurio.

Rico, A. (2008). Policías, soldados y vecinos. Las funciones policiales entre las reformas rivadavianas y la caída del régimen rosista (Tesis de maestría inédita). Luján, Universidad Nacional de Luján.

Sabato, H. (2007). La política argentina en el siglo xIx: notas sobre una historia renovada. En G. Palacios (coord.), Ensayos sobre la nueva historia política de América Latina, siglo XIX (pp. 83-94). México: El Colegio de México.

Sabato, H. (2010). Milicias, ciudadanía y revolución: el ocaso de una tradición política (Argentina, 1880). En B. Bragoni y E. Míguez (coords.), Un nuevo orden político. Provincias y Estado Nacional, 1852-1880, (pp. 227-244). Buenos Aires: Biblos.

Tenti, M. (2010). Proyectos modernizadores y elites regionales en la consolidación del estado santiagueño (1903-1916). Trabajo y Sociedad, 14(XIII). Recuperado de http://www.scielo.org.ar/scielo.php?script=sci_arttext\&pid=S1514-687120100001 00007\&lng=es\&nrm=iso.

Ternavasio, M. (1998). Las reformas rivadavianas y el Congreso General Constituyente. En N. Goldman (dir.), Nueva historia argentina. Revolución, República, Confederación (1806-1852) (t. III, pp. 159-197). Buenos Aires: Sudamericana.

Vélez Rendón, J. (2012). "Desconductadas costumbres" y "semillas de la discordia". Prácticas de oposición y resistencia a los jefes políticos en el nordeste de Antioquia (1821-1843). Historia Crítica, 47, 45-70. DoI: 10.7440/histcrit47.2012.04 
Vilchis Salazar, E. (2012). El jefe político: transformaciones en la administración pública del Estado de México e injerencia en el "contingente de sangre”, 1867-1876. Contribuciones desde Coatepec, 22, 69-95. Recuperado de http://revistacoatepec.uaemex.mx/article/view/274/267

Whalter, J. C. (1947). La conquista del desierto (t. II). Buenos Aires: Círculo Militar, Biblioteca del Oficial.

Yangilevich, M. (2006). Construir poder en la frontera. José Benito Machado. En R. Mandrini (ed.), Vivir entre dos mundos. Las fronteras del sur de la Argentina. Siglos XVIII y XIX (pp. 195-226). Buenos Aires: Taurus.

Yangilevich, M. (2009). Vida cotidiana, indígenas y cristianos en la campaña bonaerense durante el siglo xIx. En J. Farberman y S. Ratto (comps.), Historias mestizas en el Tucumán colonial y las pampas (siglos XVII-XIX) (pp. 189-219). Buenos Aires: Biblos.

Yangilevich, M. (2010). Crónicas de conflictos y desilusión. Prefecturas de campaña, juzgados de paz y comisarías en Buenos Aires (1857-1859). En D. Barriera (coord.), La justicia y las formas de la autoridad. Organización política y justicias locales en territorios de frontera. El Río de la Plata, Córdoba y Tucumán, siglos XVIII y XIX (pp. 129153). Rosario: ISHIR-CONICET.

Yangilevich, M. (2012). Estado y criminalidad en la frontera sur de Buenos Aires (18501880). Rosario: Prohistoria.

\section{OTRAS FUENTES}

\section{Archivos}

AgN Archivo General de la Nación, Buenos Aires, Argentina.

Aнмт Archivo Histórico Municipal de Tandil, Tandil, Argentina.

\section{Bibliografía}

Barral, M. E. y Fradkin, R (primer semestre, 2005). Los pueblos y la construcción de las estructuras de poder institucional en la campaña bonaerense (1785-1836). Boletín del Instituto de Historia Argentina y Americana “Dr. Emilio Ravignani”, 27, 7-48.

Garriga C. y Lorente, M. (2007). Cádiz 1812. La Constitución jurisdiccional. Madrid: Centro de Estudios Políticos y Constitucionales. 
Guerra, F. (2003). De la política antigua a la política moderna: algunas proposiciones. Anuario IEHS, 18, 201-212.

Mallon, F. (2003). Campesinado y nación. La construcción de México y Perú postcoloniales [1995]. México: CIEsAs/El Colegio de Michoacán/El Colegio de San Luis Potosí.

Mijangos Díaz, E. (2008). La dictadura enana. Las prefecturas del porfiriato en Michoacán. Morelia: Instituto de Investigaciones Históricas-Universidad Michoacana de San Nicolás de Hidalgo/Instituto Panamericano de Geografía e Historia. 